\title{
Integration of Section and Model: Reflections from a Studio Practice
}

\author{
Ugur Tuztasi $\odot$ \\ Cumhuriyet University, Faculty of Architecture, Fine Arts and Design, Sivas, Turkey (Corresponding author) \\ Pinar Koc \\ Cumhuriyet University, Faculty of Architecture, Fine Arts and Design, Sivas, Turkey
}

Received: August 12th 2020, Revised: September 2nd 2020, Accepted: September 14th 2020

Refer: Tuztasi, U., Koc, P., (2020), Integration of Section and Model: Reflections from a Studio Practice, Journal of Design Studio, V.2, N.2, pp 23-39,

U. Tuztasi ORCID: 0000-0003-3668-5665, P. Koc ORCID: 0000-0001-8727-2655, DOI: $10.46474 /$ jds. 779647 https://doi.org/10.46474/jds.779647

\begin{abstract}
This text discusses an experimental pedagogical method coded as from 'section-model to space'. The theory of the study is the integration of basic design exercises and the architectural project studio. Instead of the disconnected understanding of the architectural project studio with basic design exercises, outputs of the two studios are integrated and design processes come to the fore as a new learning setup. The main idea of the method is to find transformations from basic design models and to benefit from basic design principles in an architectural design of a building. Methods proceed through the various design variables by giving the architecture students a fixed design resource that includes practicing the space through a sectional model. The fixed variable in the design research is the output of basic design exercises. Sectional models, which are open to continuous improvement, are experimental tools that initiate a formal organization. This experiment was adopted with a ritual of repetitions; at the end of the process, practical and survey-based inquiries were carried out to test the theory. As a result, the method leads architecture students to analyze spatial design in terms of relationship between the third dimension and tectonic content. Also, it has been observed that the process offers opportunities for empirical research. It was found that the interaction in the studio environment increased with all these models.
\end{abstract}

Keywords: Architectural Studio, Design Research, Model, Section, Pedagogical Model.

\section{Introduction}

The architectural project studio is the core of the curriculum that forms architectural education. This environment, where various pedagogical models or approaches are tried, is a practical area where architectural design research is conducted. The architectural studio, based on the problem and solution relationship, is the most important learning environment for architectural students. In this profession, making critics in design studio can be accepted as a traditional method that advances and improves the architectural project. Although it has contributed to students' architectural project experience, different pedagogical models have been increasing in recent years. The constant element in the studio is that the student learns to make an architectural project or to design a building/urban area. The act of design is shaped by processes such as creativity, problem-solving, thinking, learning, perception, scientific research and their variable components (Ertürk \& Ertürk, 2019). In addition, the equipment and methods of

Journal of Design Studio, v:2 n:2

Tuztasi, U., Koc, P., (2020), Integration of Section and Model: Reflections from a Studio Practice, 
architectural design research are more or less clear. Idea sketches, presentations produced by drawing, modelling and computer-based software are concrete representations of design behaviors towards problem-solving, and the direct result focuses on the product. In parallel with the architectural studio, basic design education is based on the concept of discovery. It is assumed that the student will learn by discovering, in line with certain principles, and develop creative thinking skills (Yaşar, 2020). Therefore, while basic design education offers a learning environment where knowledge of how to design is discovered, architectural project studios are designed with traditional or different pedagogical models to produce solutions to design problems on a floor that extends from single building scale to urban scale.

Basic design or architectural design studio explores and experiences at any level of architectural education. Discovering and experiencing is one of the ways to grasp design process awareness and educational process awareness. Experimental learning theory defines knowledge as the information created through the transformation of experience (Kolb $\&$ Kolb, 2005). In that case, learning to design throughout design research stems from the potential for experimentation and discovery. The case-study discussed in this text consists of design research in which the potential for experimentation and discovery is increased. Rather than the disconnected understanding of the architectural project studio with basic design exercises, in this study, the integration of the resultant products of the two studios will increase the potential of experience and discovery, so that the architectural project process will move from learning to design rather than being result-oriented.

Basic research idea of this study is to provide an environment which basic principles of design gained in basic design courses can be transferred to upper class architectural design studios. The main framework of the present study consists of increasing knowledge from experience and activating the potential for discovery of design process awareness. For this purpose, integration of basic design exercises and architectural project studios, in terms of final products, has been provided by Sivas Cumhuriyet University's, Department of Architecture, and a new environment has been developed in which the design process tends to reveal design process awareness through knowledge from experience. Such architectural design research is directly related to the curriculum applied by the authors of this study, which conducts both the architectural studio and the basic design studio at Sivas Cumhuriyet University's Department of Architecture. In the basic design studio, as a priority application form, a new method in which a student can grasp three-dimensional thinking through a model is concentrated on. Three-dimensional studies on specific themes are also consistent parts of a methodological framework based on spatial inquiries. The process, starting from the ground-surface-cover concept and continuing with structural analysis, is enriched with spatial readings and formal exercises. In this variety, by studying the basic mass set up as a learning outcome for the first-year students, whose three-dimensional thinking skills are increased with a continuous model, without any search for any function, only by working with sub-base, upper base, lateral surfaces, material relation, structural design and formal attitudes. Thus, the educational output is transformed into a visualized, rich design knowledge. However, such an output of basic design education is left behind in upper-class project groups. Through production models, architectural production for formal composition is abandoned and a return to traditional studio habits is experienced. This attitude is the point that makes this design research useful. Design research implies here that data collection activity is transformed directly and concretely into a series of discovering-experiencing and doing-thinking activity in the studio. Accordingly, it can be here stated that the idea of integration of architectural studio and basic design studio emerged a vertically structured inter studios. Because, thanks to this studio, it aims to develop "the ability to establish functional and aesthetic structural arrangements" (Alangoya, 
2015, p. 86), which are expected to spread especially to the architectural project production process.

The origin of the study is based on basic design exercises. The diversity of basic design education helps to obtain different and more comfortable design behaviors; however, since the architectural project groups in the upper classes are presented with more restrictive content such as context, function and location, often design results that cannot go beyond the traditional methods have been encountered. Therefore, the fact that the design behaviors gained in the basic design education in the first year cannot be transferred to the projects in the upper classes reveals the necessity of the research. The most important element of this study, which aims to increase the potential of experience and discovery, is the model; this comes from the outputs of basic design education. Since the basic design exercises provide more flexible and comfortable design outputs, potential of experience and discovery is instinctively progressed in the studio. For example, in a formal exercise, a form is transformed and reshaped countless way according to the limits of cognitive, perceptual and intuitional behaviors. In this study, the integration of the resulting products was carried out as follows: functional, formal, spatial, structural and structural study of the sectionmodels, which were designed as a design exercise by the first-year students as part of the basic design course in the fall semester of the 2017/2018 academic year, are given to the 3rdyear project group in the spring semester of the 2017/2018 academic year. Then, these sectionmodels are transformed into a spatial problem by the 3rd-year project group in an urban space. In short, this experimental studio is a fiction that includes more concrete transformations towards architectural space based on abstract sectionmodels.

\section{Conceptual Framework: Integrated Composition of 'Section and Model' in Search of a New Pedagogical Model}

The traditional studio environment in architectural education is a teaching format based on a master-apprentice relationship and a process managed with weekly criticisms. According to Ciravoğlu (2014), this system may create some problems such as replicating the tutor's architectural approach, lack of responsibility for the student, lack of assertiveness in the project, lack of selfconfidence and awaiting permanent approval. Of course, it should not be overlooked that previous statement depends on the pedagogical approach of the tutors of the studio. Therefore, many pedagogical models for architectural studio education have been developed. The most recent source that presents these models most compactly is Salama's "Spatial Design Education New Directions for Pedagogy in Architecture and Beyond" (2015). Instead of focusing on the variety of pedagogical models currently on a quest, this text touches on the student's expectations from the studio. According to Goldschmidt (1983), this expectation is about how to make the design initiative (move), how to start it, how to decide its sequences, as well as the next ones, how to use the previous inferences, how to discover mistakes and how to decide on priorities. This situation can be fulfilled completely by manipulating the design thinking in the studio environment and taking an ameliorative position. Another reason for the emergence of different pedagogical models should be to better analyze the dynamics of the learning processes and to know the design thinking or the ability to design more closely. Oxman (2004) explains that experimental approaches in design education include theoretical foundations for modeling based on cognitive theories of thinking, creativity and learning, and that conceptual knowledge is obtained in design as well as the cognitive process through modeling. In addition to how the student will design, he states that he will work as a design researcher while learning about design. From the perspective of this paper's research problem, previous statement can be commented that thinking, creativity and learning in design can be transferred from a theoretical foundation to practical application. Here, tools for practical application and learning about design are basic design principles and exercises. 


\section{Journal of}

Design Studio

$\mathrm{v}: 2$ n:2 December 2020

In short, the main aim of design education is to provide different design experiences, to take an active role in different design areas, to improve knowledge acquisition, and to provide a strong communication and motivation environment (Paker Kahvecioğlu, 2007). Similarly, the role of the design studio is associated with the learning and application of new skills and a new language, as well as learning to think architecturally. The educational experience in the studio also involves the simultaneous interrelation of these three steps, mentioned above (Demirbaş \& Demirkan, 2003).

Galle (2011) argues that it is not possible to teach design without addressing creativity, ideas, and goals. He emphasizes that there should be criteria such as public acceptability, appropriate scope and exploratory potential in the definition of design. Therefore, it is a very challenging task to discover design thinking and to develop the ability to design. The first step of this work is to abandon the traditional studio environment and to construct an experimental new process. Secondly, it is important to make the idea of a design more understandable. According to Goldschmidt (2017), design thinking consists of small steps that carry the designer's reasoning throughout the design process. Reasoning, which includes design thinking, becomes concrete with a design output. This process, which turns into design research, is shaped with different concerns. For example, research methods used to obtain a design output or the degree of contribution of design tools such as drawing and modelling characterize the processes of new pedagogical models. The design process is the constant change between sensory-rational, abstractconcrete, form-content dilemmas. The research based on design is about how the form is produced, what method is used, what are the motivations, how they are used in constructing content, and how the content is defined (Voet, 2013). There is also an effort to make the design process and thought process more understandable in the studio setup, which was designed within the context of this text. In this new experimental pedagogical model, the section-model has been accepted as the primary design tool that enables the production of the shape. These primary design tools were brought directly from the basic design exercises as a requirement of the theory of the study, and the models that have already been produced were used as initial ideas/droplets for formal searches. Thus, three-dimensional models produced through basic design exercises are included in the design process of the architectural project studio. Sensory-rational thoughts, abstract-concrete relations and formcontent definitions in other parts of the process are left directly to the student's ability to design. The only constant that does not change here is to provide a formal organization with the use of section-model as design tools. However, the process based on design research was based entirely on existing formal models, which changed the design experience by keeping the exploration potential on the alert throughout the design process.

The use of formal models brought from basic design exercises, as an initial idea in the architectural studio is, of course, closely related to the qualities of basic design products. Threedimensional models produced as part of a formal and material-based exercise are open to development like all models and have a clear spatial layout and formal structure. Although the model is generally associated with architectural representation, it has been accepted as an immediate design tool for doing and thinking in this study. The model expresses the illusion of reality and is the most intimate manifestation of the architectural concept (Reynolds, 2015). The models that are the subject of the study are sectional models that appear as design exercises in the basic design education process. A model in this pattern consists of an unfinished and exposed wall, floor, material, facade pattern, structure, or circulation elements in a mass organization. Therefore, such a model is a way of learning structural components, structural elements and formal composition for first-year architecture students. This model, which can be called the section-model, ultimately offers a formal composition. The reason why the section-model 
is preferred in this process is that it provides more insight into the details such as a converging lens regards the third dimension of a mass mechanism. According to Arnheim (2009), the section does not have integrity in the plan, but it has distinctions between the upperlower-lateral surfaces and offers only vertical integrity. In other words, the section contains details on formal-structural relations, on the one hand, and it carries inspirational tips for mass organization. Sections are the product of a design exercise where many structural components are exposed. More specifically, the section-models used in this study are like a design object ready to add, remove, deform and reshape. In this context, as the architectural research progresses through the process, constantly changing design ideas can express themselves as an architectural concept in the working model. Instead of finished, completed mass assemblies, working models that are open to continuous development are a manifestation showing how design thinking has taken the lead. As Asar (2018) emphasizes, the model provides intuitive processing of blurry mental images and establishes them in three dimensions as a design tool that enables discovery in architectural design and appeals to visual and tactile senses simultaneously. Thus, when the working model is combined with a level where the cross-sectional relations in the mass assembly can be read, the architecture gives way to a new learning method in the studio.

\section{Method}

The main idea of the method is to find transformations from basic design models and to benefit from basic design principles in an architectural design of a building in the same section-model in multiple different phases by different students who continue working on the same model. In the process of applying the method, which we will encode from 'sectionmodel to space', the design tool that enables the re-formatting of the section-model as an architectural production is directly the fiction of the 'section'. The most direct way to analyze the three-dimensional formal composition that we encounter as an incomplete mass arrangement is to establish sectional relationships, as one way to create an architectural correlation among many exposed components is to resort to various deformations and transformations; another way is to reveal sectional relations between structural-constructional-formal mechanisms because of the cognitive and perceptual processes.

This method can be interpreted as a top-down attitude: as a model designed to test the theory referred to as from 'section-model to space' code. In the experimental studio, the basic design outputs of the first-year students, in the 2017-2018 fall term, were compared with the third-year students in the spring term of 20172018. In other words, the group that makes the 'models' is comprised of first-year students; the groups that study the 'models' and turn them into 'spaces' are comprised of third-year students. The stages of the experimental process were managed as follows: the process was arranged with three intermediate deliveries of three weeks and the final delivery of three weeks. The section-model, which was the subject of the final delivery only, was not brought from the first-year students; the thirdyear students were asked to perform spatial analysis on a new section-model with a similar design behavior from the 'section-model to space' code. In summary, the models used in the interim submissions consisting of three-week processes were the basic design outputs of the first-year students, and the same method was expected to be obtained by trying these models in the third-year students three times with three different models.

In the first phase, 16 sectional models were distributed among randomly created groups of students (Figure 1). These groups consisted of 2-4 people and care was taken to create a differentiated combination of students in terms of ability. The aim was to determine how the differentiated students comprehended the same model. Another aim was to determine whether student's ability was positioned in line with the habits in the traditional studio, whether it would change when a different design method was encountered. Another point to note is that since 
there were three intermediate stages until the final delivery, the three section-models were distributed between different groups to obtain more diversified results. For example, the group using section-model 1 in the first phase considered section-model 13 in the second phase, and section-model 11 in the third phase. Likewise, the group using section-model 13 in the first phase designed section-model 6 in the second phase and section-model 1 in the third phase. Again, in the first phase, the group that used section-model 11 considered sectionmodel 7 in the second stage and section-model 13 in the third stage as the design object. Despite partial intersections in the distribution of models, this difference facilitated the method to provide more consistent results. This eliminated the concern that the architectural production made by three different groups of students through the movement of the same three section-models in each phase could lead to similarities.

The evaluation of the design program, consisting of three interim deliveries of three weeks, was as follows: first, the most successful examples of the 16 section-models, regardless of the group, at the end of the first, second and third phases, were determined; secondly, a comparison was made between the first, second and third phases of the 16 section-models and the resulting product in the final phase. Comparison parameters for three phases and final phase are defined by the relationship between architectural solution's feature and ability of transformation section-model. This relationship is comprised of holistic architectural view. Criteria for evaluation of section-models is identified with formal organization, spatial-structural consistency, intelligibility of mass and appropriateness of functional solution. Thus, the evaluation tried to determine what impact the first three phases might have on the final product and how the method contributed to the design skill was discussed. More specifically, since the model subject to the final delivery was not brought from the first-year students, in the final phase, we tried to determine whether the sectionmodels, which were considered as design objects in three phases, were used and how much the three phases contributed to the final study so far. In fact, with this comparison, scenarios related to the situation in the improvement and decline were examined. Thirdly, the study analyzed how the same model was handled by different students. Thus, through the findings obtained, it was discussed whether any design behavior could be developed in the method we encode as from 'section-model to space', and whether this could be constructed as a learning model in architectural education.

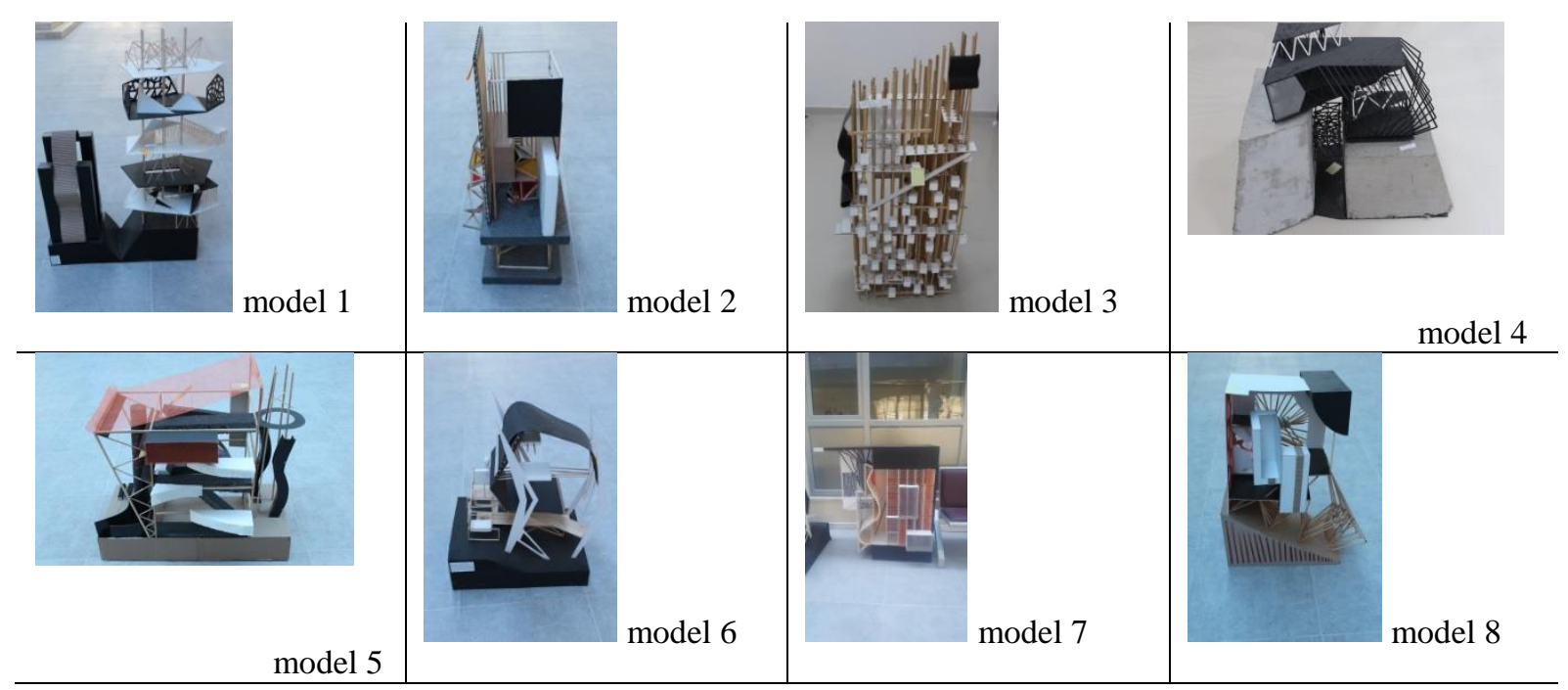

Journal of Design Studio, v:2 n:2

Tuztasi, U., Koc, P., (2020), Integration of Section and Model: Reflections from a Studio Practice, 


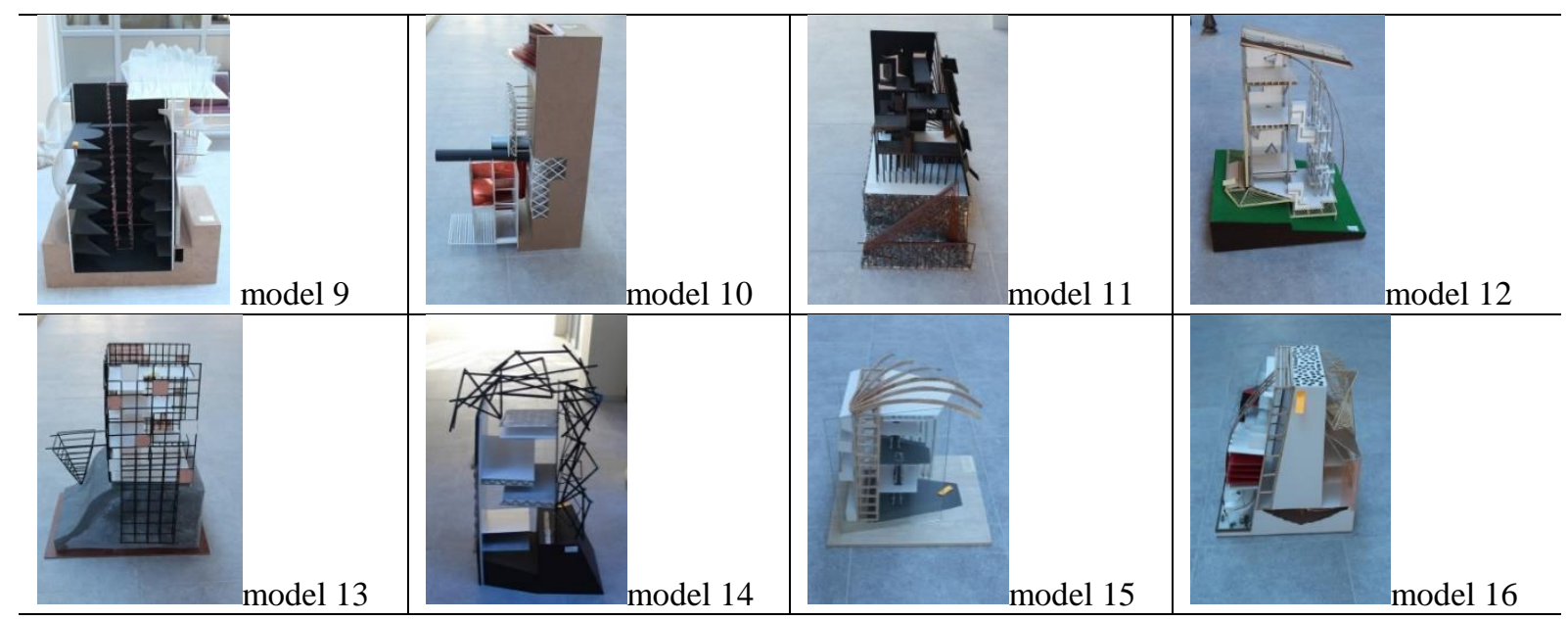

Figure 1. Section-models that constitute the basic design output and given to the third-year students.

\section{Findings of Experimental Study and Discussions \\ 4.1. First Discussion of Method}

In this method, which we encode as from 'section-model to space', the first research area that the findings will come from will focus on examining the most successful results in any stage among the 16 section-models. The purpose of examining successful examples is to determine whether there is an internal design behavior or a common design decision in the final product. Successful examples are defined by using comparison parameters and evaluation criteria such as formal organization, spatialstructural consistency or appropriateness of function. In the first evaluation among the 16 section-models, it was determined that nine of them were turned into a successful product in any design phase. Accordingly, three successful products were obtained in design model 1 , two in models 6 and 12, and two in models 2, 5, 8, 13, 14 and 15. This result showed that two students (Student 1; Student 2), among those who reached this final product, exhibited successful results also in the three design phases of the method. This situation is related to the achievements of the relevant students above the average of the class in the traditional studio environment; they also showed the same level of success in their studio from 'section-model to space'. Similarly, two students (Student 3; Student 4) provided successful examples in two of the three design phases. Hereby, the following determination should be included. Namely, unlike those who achieved successful results in all three design phases in this group, only one of the students had a higher than average class level in the traditional studio setting. In other words, discussing the successful products produced by considering the three design phases, it has been determined that the students with a success level above the average of the class in the traditional studio environment continued the same success level from the 'section-model to space' studio. This method also contributed to the production of more successful products among several of the intermediate students.

Some examples of the first phase of the studio are presented here. It was stated that Student 1 was successful in all design phases among the three students who took section-model 1 at any stage during the studio process and took it to a successful result. The other two students (Student 5; Student 3) who achieved successful results with section-model 1 were able to achieve successful results in two of the three stages of the design phases. To clarify this situation, the way of handling section-model 1 will be discussed. Accordingly, Student 5, who treated the model as a design object in the first design phase, adopted a solution strategy in the axis of mass and front movements. The project 
was designed as the Cultural Center and the Performance Hall and was located in the southwest line of Sivas city center, known as Gültepe District, where there are more slum buildings, remained strictly connected with the model's dynamism (Figure 2).
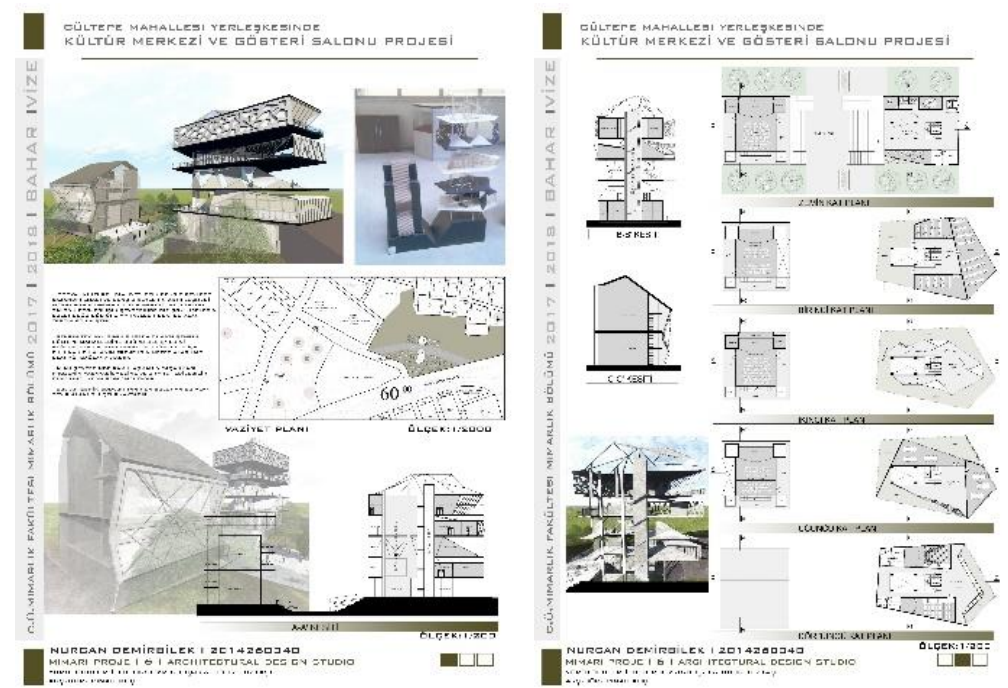

Figure 2. The first successful product in the design of section-model 1.

Student 3, who studied model 1 in the second design phase, stated that she used the occupancy-space balance in the model as his analysis strategy. Again, in the south-west line of the city, in Karsiyaka region, which consists of low-rise houses as a texture detached from the urban area, section-model 1 was designed as the Expo Tower. The student grasped the black colored parts, which express that the three models were filled as closed spaces and the white colored surfaces that provided the vertical elevation as open-semi-open spaces (Figure 3). Taking section-model 1 in the third design phase, Student 1 designed the Architectural Heritage Museum inside the park behind the historic governorate building in Sivas city square. As the analysis strategy, the V-shaped area connecting two separate parts of the model was abstracted and a more rational cult arrangement was adopted at the base (Figure 3). While Student 5 saw the existence of different facade and floor combinations in each level as a compelling factor during the massing of the model. The compelling situation for Student 3 was that there are too many gaps in terms of full-empty rhythm and its location in the plan organization. Student 1 emphasized the differences between the floors and stated that it was difficult to establish the connection between the floors. However, with the interventions made in terms of space and facade, successful solutions were achieved even though the model was changed. In other words, instead of accepting the section-model as it was, a consistent result was pursued by considering all the formal, spatial, functional, contextual and structural components. For example, Student 3, who transformed the model into the Expo Tower, stated that formal interventions were made in the interior solution under spatial operability. Similarly, Student 1 performed a more rational intervention for indoor solutions and most of the openings on the vertical line of the model were turned into a closed space. All three students did not make a comprehensive change in terms of the facade (Figure 3 ) 


\section{Journal of}

Design Studio

v:2 n:2 December 2020

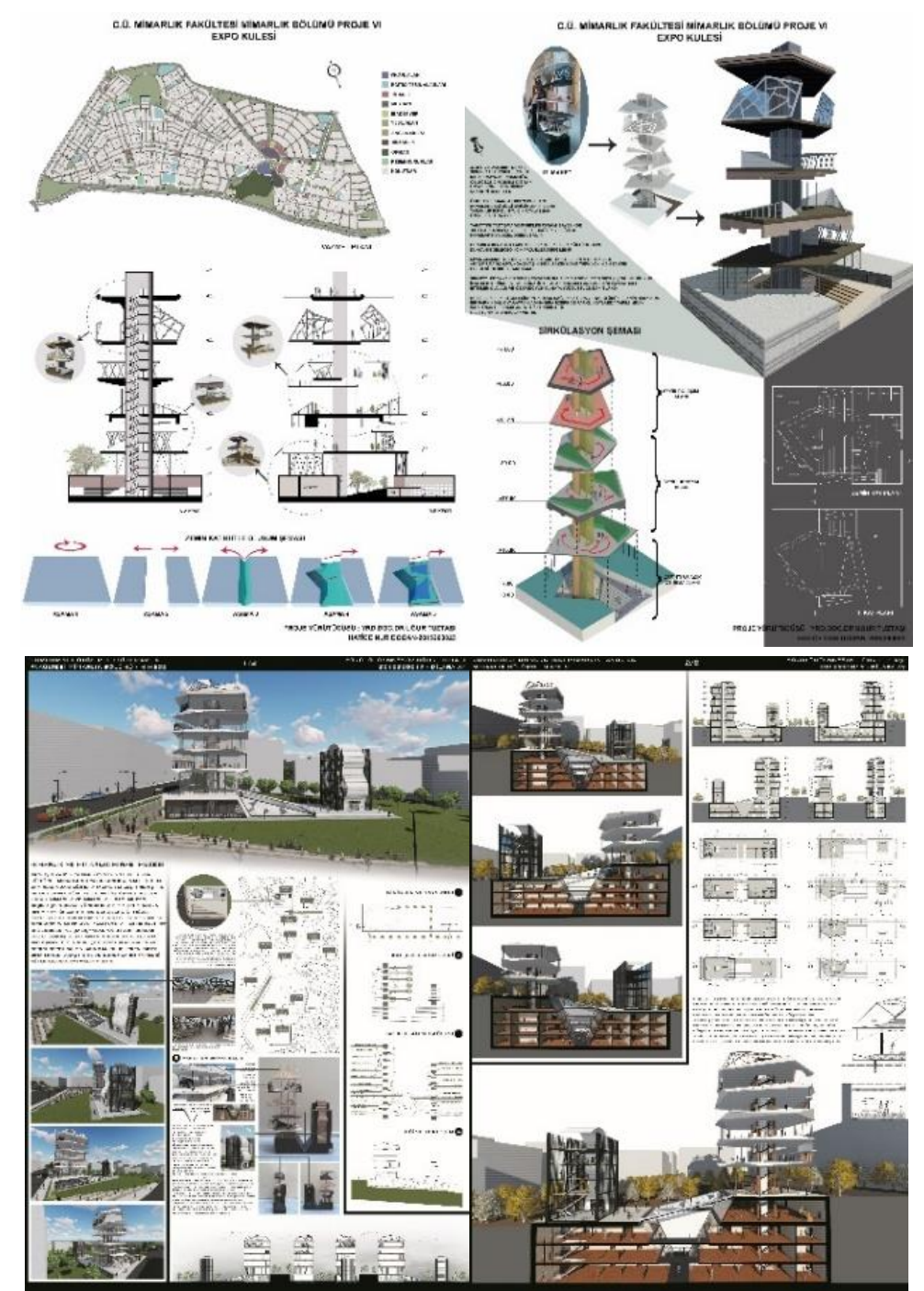

Figure 3. Examples of other successful final products in the design of section-model 1.

In section-models 6 and 12, the main lines of the current model were used as a common design attitude. Although the model was designed with different programs by each student, the deformation of the existing floor path appeared a common attitude in the formation of the shape (Figure 4). According to the relevant surveys, weak correlations in circulation and spatial configuration were defined as the difficulties encountered. Although section-model 2 was handled by a total of 10 students in the three design stages, only one student was found to be successful. One reason for this may be that the present model offers an undefined inner space. However, this uncertainty has been shown as a comfortable workplace in a successful product. According to the survey, Student 2 stated that he could think more freely thanks to the absence of a pronounced floor arrangement. Despite the difficulty in constructing a consistent circulation, more flexible interventions were made to the lacunar model (Figure 4). 


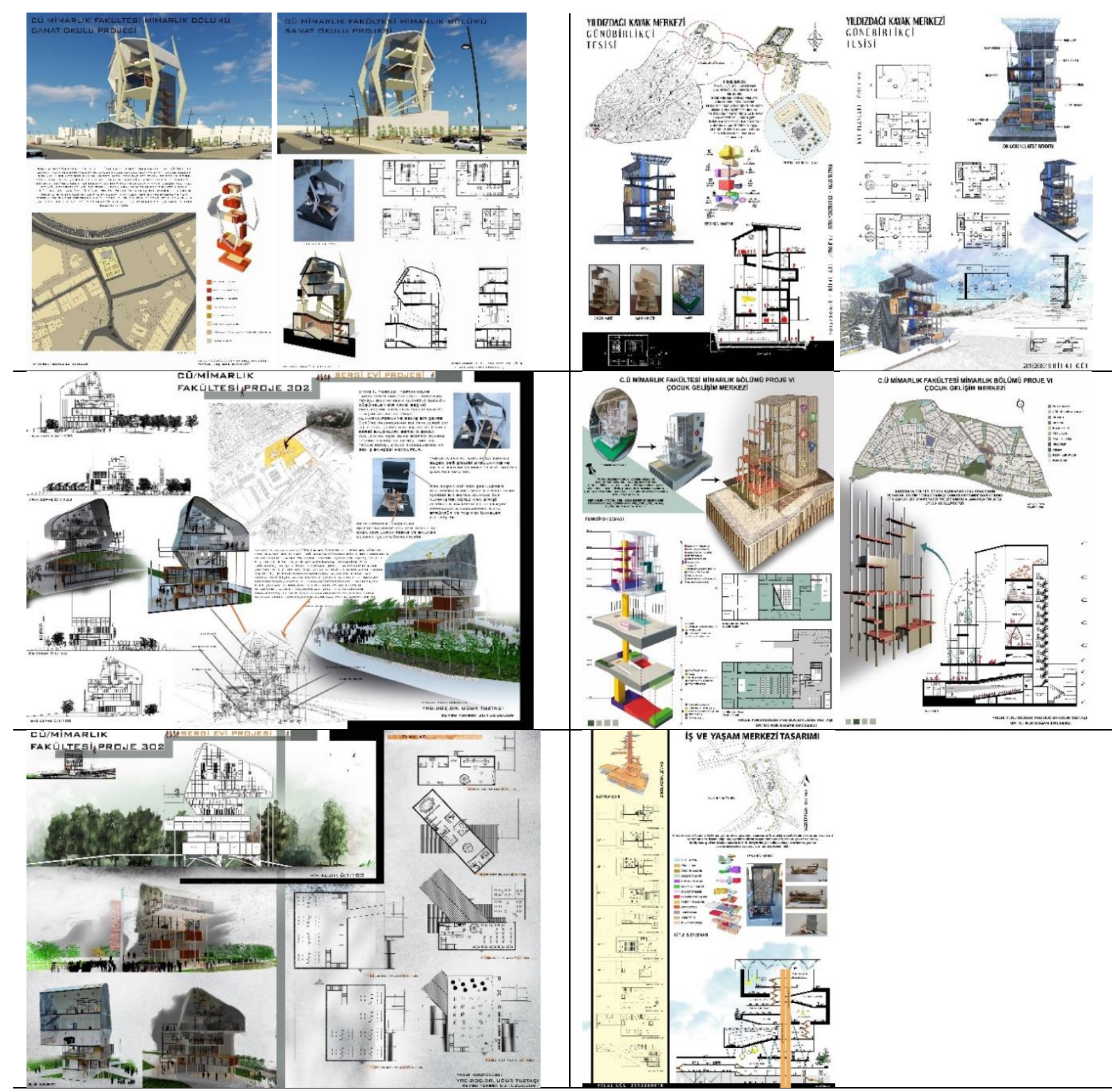

Figure 4. Examples of successful final products from section-models 6, 12, and 2.

In short, the common design behavior in all section-models that emerged as a successful result at the end of the first phase was due to a good reading of the formal layout of the existing model and the use of design tools such as abstraction, addition-extraction or deformation when necessary. Firstly, organizing the format was pursued. The functional mechanisms of the formal-spatial arrangement such as circulation, wet volume or layouts remained secondary design problems.

\subsection{Second Discussion of Method}

Apart from the evaluations made in the first part, another method of evaluation is to create a scenario on progress and decline/pause. In this sub-section, the first, second and third phases, as well as the final product will be compared over the appropriate samples to be selected from the 16 section-models. There are two main goals to be achieved in this comparison. The first is to determine how effective the 'sectionmodel to space' method can be in the final study. The second goal is to reveal whether 
there is any progress and/or decline/pause over the student's performance and motivation throughout the process.

Accordingly, an example that shows improvement will be presented first. Student 6 worked with section-model 6 in the first phase, section-model 2 in the second phase, and section-model 4 in the third phase. Although the lacunar structure of the model in the first phase was a challenging factor for Student 6, in this way, space organizations with different dimensional and formal variability were realized on the inner surfaces. Student 6, who faced a lacunar model in the second phase, showed a design approach similar to the first phase and stated that it was more challenging to deal with the circulation and analysis of wet volumes in model 2. In other words, Student 6 experienced the establishment of a solid-void balance in a formal organization in the first stage; when she encountered a similar design model in the second stage, she easily applied the design information he had internalized in the first stage to the functional concerns in the second stage, and the compelling factors were replaced by functional concerns. While the final product of the model in the first stage had a very uneven mass arrangement, the final product of the model in the second stage turned into a more consistent mass organization and even the front layout was designed to be more readable. In the third stage, Student 6, who worked on a model with more clearly defined surfaces, was able to easily make changes in the interior layout of the model in accordance with the functional requirements in the last stage (Figure 5). Student 6, who designed a new section-model for the final project, proposed a Business and Life Center in the city center. Student 6 stated in the survey that the other three phases did not limit her in the final stage. Stages of sectionmodel 2 and section-model 4 were determined as the most effective models on the final process.

In this architectural design experiment, some students developed at every stage, as well as students who experienced decline/pause. For example, Student 7 used the existing pattern of models in all three stages as they were, she designed them for three stages by preserving the structural and textural properties of the material on the model surface. As a result, formal organizations obtained through the dynamics of the mass order of the present model emerged. Sticking to the existing model to such an extent sometimes led to the development of false structuralfunctional-spatial solutions in the final products. The subject that Student 7 struggled with in the first stage was how to use the metal mesh that provides the mass end of section-model 9; in the second stage, while there was an indoor organization problem arising from different flooring paths, in the last stage, there was a difficulty in functioning the model (Figure 6). In other words, Student 7 had difficulty in perceiving the section-models in each phase and had difficulty in transforming the mass mechanisms of the models into design information. In final project, Student 7's design was a formal organization that had lost its dynamism. As stated in the final survey, Student 7 was not affected by the other three intermediate stages in the final study and handled the final product independently of the intermediate stages. 

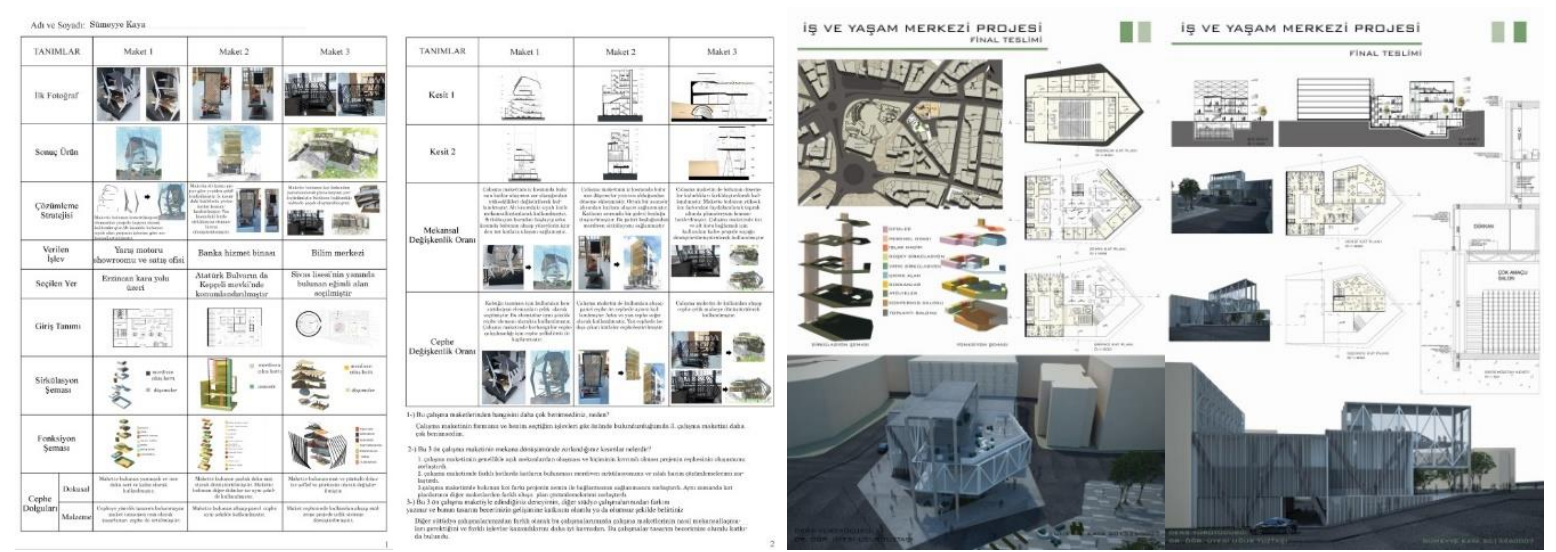

Figure 5. An advancement scenario through section-model and final project.
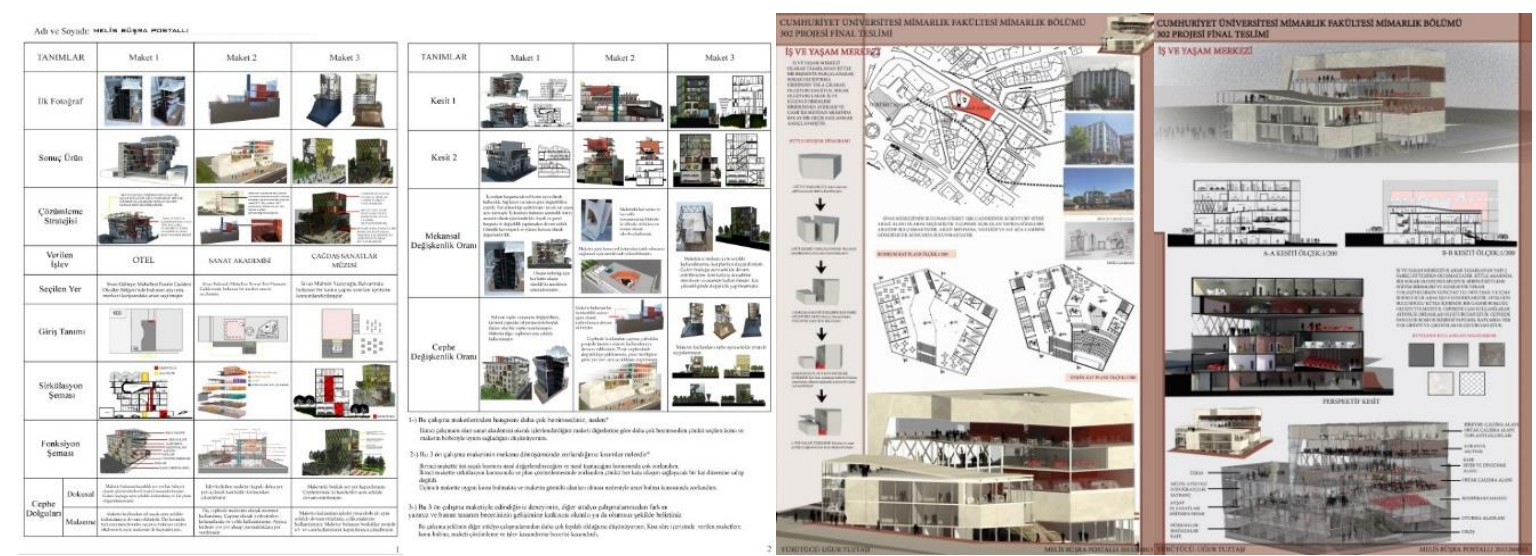

Figure 6. A decline/pause scenario in design through section-model and final project.

Considering the final study of Student 7 and Student 6, the contributions of the other three intermediate stages were as follows (Figure 7): according to Student 6, who learned something from every different section-model in each phase and put it above design knowledge in the next stage, the final work was entirely the result of the previous three phases. According to Student 7, the three intermediate stages did not make any contribution to the final study. Comparing the final studies, Student 6 demonstrated consistent and nourished design behaviors in terms of the interior organization, the sectional relationships of the building, and the dynamic shell of the mass. While the interior layout ensured the establishment of a richer sectional relationship, a facade pattern that flowed from the inside to the outside and developed spontaneously emerged in the balance between interior and exterior. In the project of Student 7, because the mass and section were not studied sufficiently, superficial relations were established, just like in the intermediate stages, and new surfaces were designed for the facade pattern that did not feed on the rhythm between the interior and the exterior. 


\begin{tabular}{|l|c|c}
\hline $\begin{array}{l}\text { When you evaluate the contribution of your 3-stage design work to your final design } \\
\text { in the studio experience, rate the options presented below (5: too much, 4: too, 3: } \\
\text { partially, 2: less, 1: very low, 0: none). }\end{array}$ & $\begin{array}{c}\text { Student 6 } \\
\text { (advancement) }\end{array}$ & $\begin{array}{c}\text { Student 7 } \\
\text { (decline/ } \\
\text { pause) }\end{array}$ \\
\hline Contributions to space design through section reading & 5 & 4 \\
\hline Contributions to associating material and space design & 4 & 4 \\
\hline Design achievement in the practice of thinking space with a model & 4 & 4 \\
\hline Design achievement in constructing place-space relationship & 4 & 3 \\
\hline Achievement in functional analysis skills & 4 & 3 \\
\hline Contribution to the resolution of facade and mass legibility & 4 & 3 \\
\hline Contribution to tectonic (constructive-structural) thinking & 4 & 3 \\
\hline No design achievements & 0 & 4 \\
\hline
\end{tabular}

Figure 7. The way the subject was perceived by students with a progress and decline/pause scenario.

\subsection{Third Discussion of Method}

Third, how the same model was handled by different students will be discussed, and section-model 11 is used as exemplary model for this discussion. Section-model 11 had three distinctive features; the first was the sub-base plane. The base plane consisted of two elements: one was the raised floor line on which the main body of the model sat; the other was the intertwined top covered side area that continued at ground level and was described as wood material. The second distinctive feature of the model was the floor paths of different heights that made up the main body. At the same time, the position of the columns holding the floor traces of varying shapes and sizes and prisms attached to them at different levels and in different ways were also prominent features on the inner surface of the present model. The third distinctive feature of section-model 11 was the outer shell framing the inner surface on both sides and their junction, depicted, again, with wooden material (Figure 8).
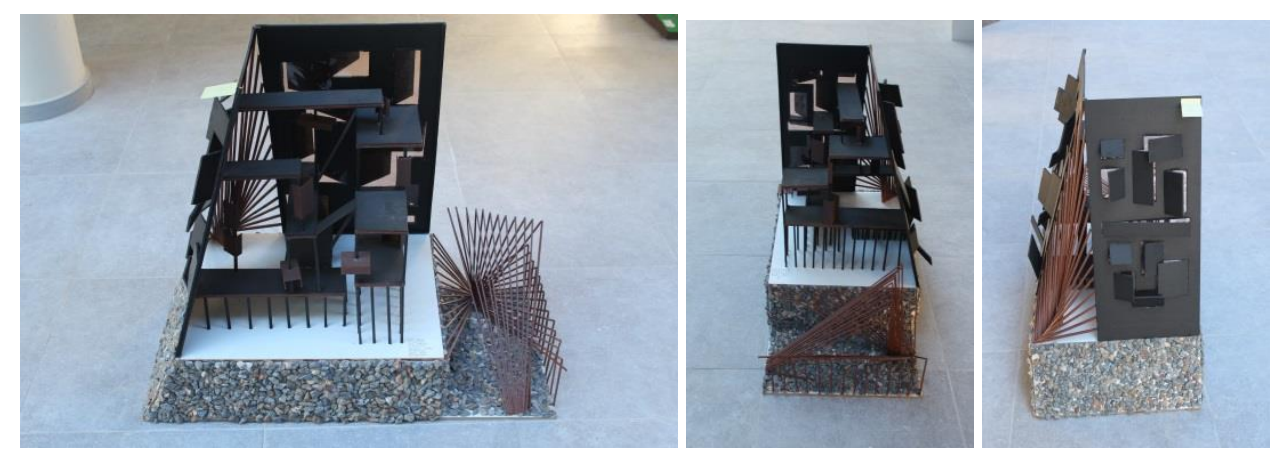

Figure 8. Section-model 11. 
Student 8, who dealt with section-model 11 in the first phase, was at the top of the class average in the traditional studio experience. However, Student $\mathbf{8}$ showed a weak performance with section-model 11 in the first phase when she started working. Designing a cultural center on the busiest street of the city, Student 8 set out from the prisms on the inner surface of the model as her analysis strategy. The existing flooring themes were used as they were and were considered as a way to obtain spaces with galleries. However, the interior section of the resulting product offered a mass space defined by very lacunar and weak relationships. The facade was also differentiated from the existing model and gained a more composite appearance. In the survey, Student 8 stated that she had most difficulty in organizing the gaps in this model. Although she reported that working with three different models led her to do more research, the section-model experience for Student 8 resulted in difficulty in reading the mass organization of the model and transforming formal relationships beyond functional-spatial concerns (Figure 9).

Student 9, who tried section-model 11 in the second phase, was at the average level in the class. Designing a technology school in the area known as the school district in the city, Student 9 started by reading the mass order of the existing model as the analysis strategy. Student 9, who started to design from a correct point, had difficulty in finalizing the model. This difficulty was probably because he handled the model in the second phase, although he initially achieved a correct starting point. Student 8, on the other hand, could not determine how to deal with the model she encountered in the first phase, while Student 9 learned from the design experience in the first phase and found a more successful starting point in the second phase. Accordingly, using the thickness of the lower floor, he divided it into units that functionally needed larger volumes. The spaces in the interior area of the model were reshaped and the prismatic masses attached to the support legs in the existing model were removed. In other words, under functional requirements, spatial solutions were realized by undergoing existing model deformation, which resulted in the product emerging as a solution that denied the relations of the existing model. On the other hand, section-model 11 for Student 9 offered a mass that was more suitable for spatialization than the other models he worked with (Figure 9).

Finally, Student 10 experienced the sectionmodel 11 in the third phase and produced an outcome defined by more consistent relationships both in the traditional studio and in other projects of the section-model process in the other two phases. Section-model 11 was designed as a library building within the university campus. Student $\mathbf{1 0}$ designed his analysis strategy on preserving the existing lower floor, reshaping the floor paths inside the model and removing prismatic bodies attached to the columns from the model. Just like Student 9, Student 10 went through a formal deformation; however, unlike Student 9, he added a strong vertical circulation body to the model. When the interior is examined in the context of sectional relations, it can be said that Student 10 reached the best solution. However, Student 10 was not able to reflect the skill level captured on the inner surface of the model in terms of the facade (Figure 9). 


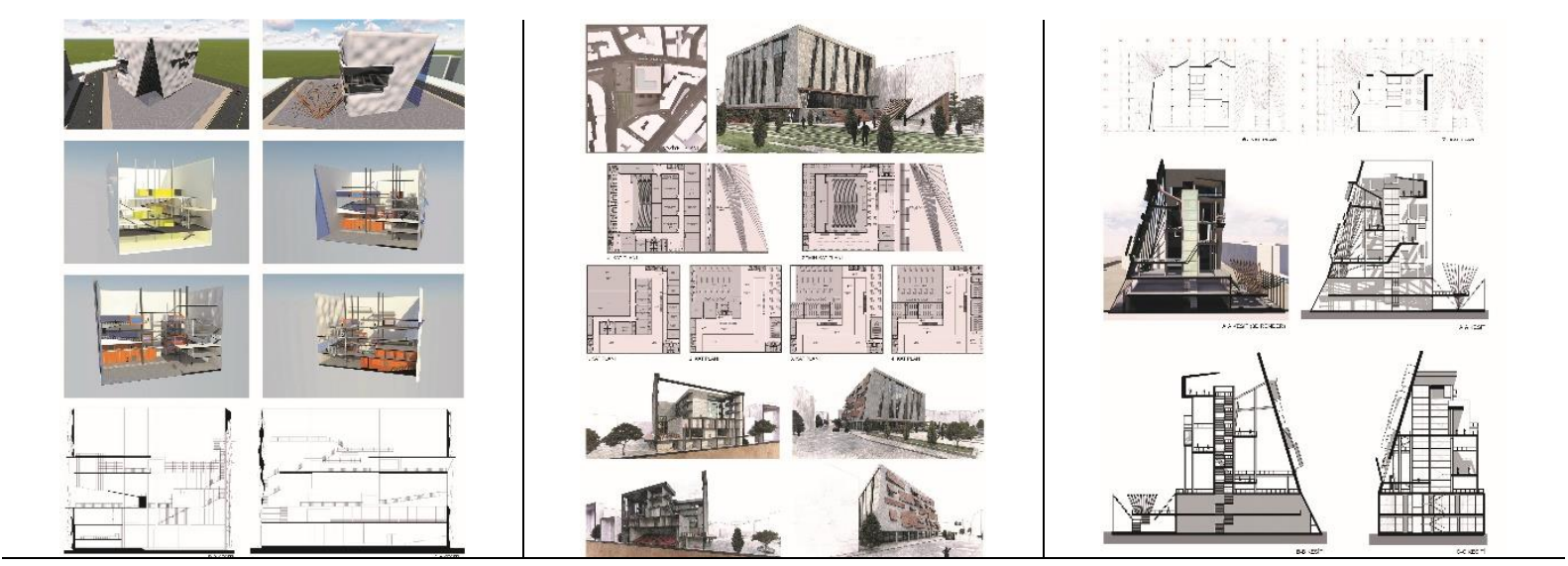

Figure 9. Examples of how section-model 11 was handled by different students: student 8 in the first phase, student 9 in the second phase and student 10 in the third phase.

At the end of this experimental studio, a questionnaire about the process was carried out (Figure 10). The questionnaire was focused to reveal that to what extent this experimental studio was contribute to student's design process awareness and educational process awareness. For example, this studio process was caused students to think with models. While models were formed and deformed and reformed, student's ability of seeing and thinking three-dimensionally was increased. In the questionnaire, this contribution was marked mostly as well as free and flexible design practices. On the other hand, holistic design grasp is improved and thus, plan, section and elevations were integrated more genuinely. According to the questionnaire, spatial compositions were seen purely since the section-models were played a role to analyze three-dimensional structures easily. Thus, functional, spatial and structural organizations were analyzed better. Contrary to traditional studio practices, this experimental studio was led students to do more research than other terms. Moreover, student's attention was turned into the studio completely since the models and phases were differantiated during the whole term. Thus, curiosity was emerged and interaction in the studio was increased automatically. These contributions were marked mostly in the questionnaire although some of the students did not pay attention to interact with others. As a matter of fact it was revealed in the questionnaire that 'sectionmodel to space' studio was seen from the point of quite diversified views. In figure 10 it should be understood that a confusion between the 'section-model to space' studio and previous studios was emerged since the common design strategies were employed because of the resemblances were derived from the nature of architectural studio. 


\section{Journal of}

\section{Design Studio}

$\mathrm{v}: 2 \mathrm{n}: 2$ December 2020

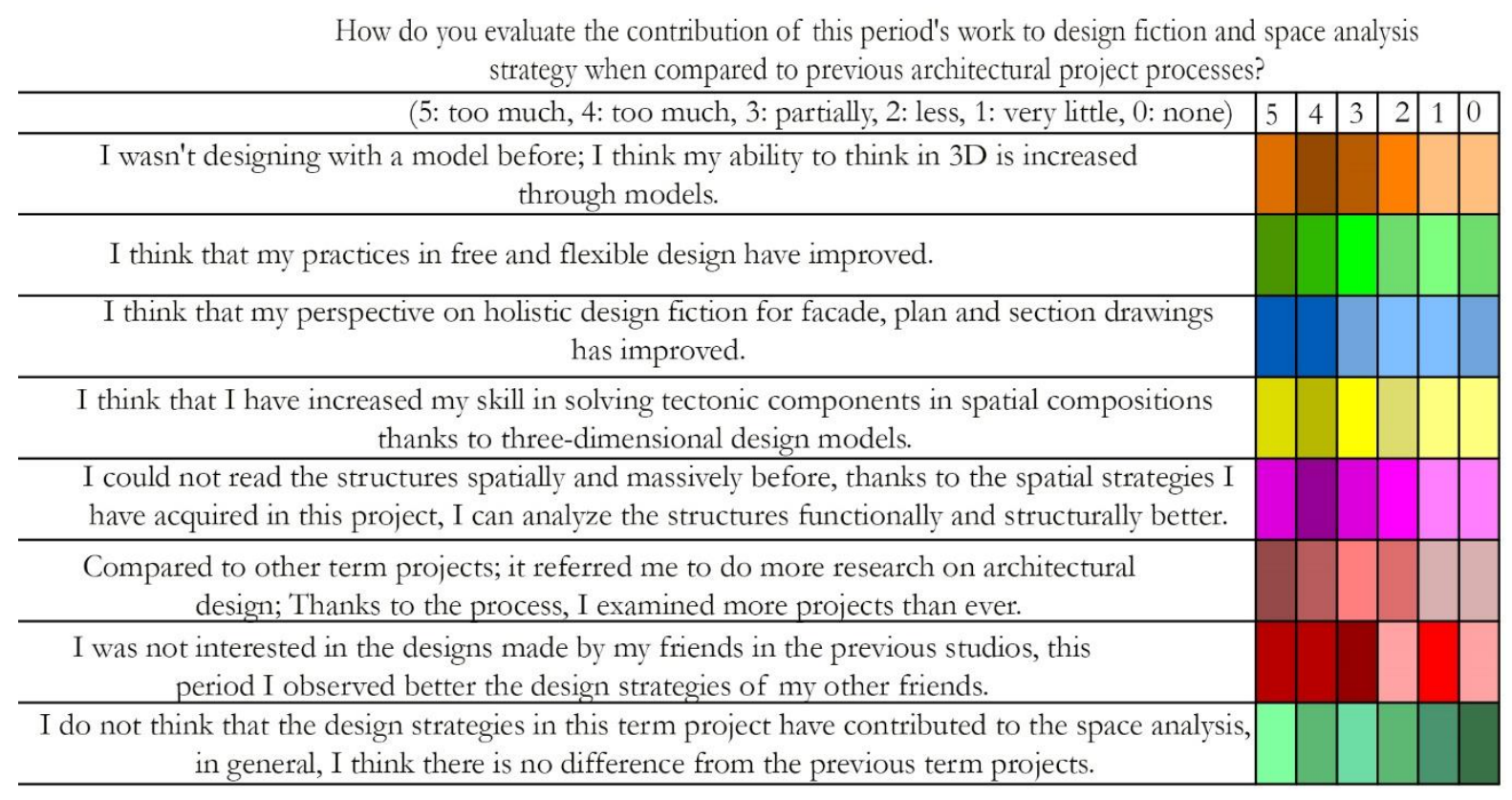

Figure 10. Evaluation of the process by the students (dark parts indicate that the answers are concentrated and light-colored parts indicate that the answers are diluted).

\section{Conclusion and Implication for Practice}

This study, which was theoretically coded 'from section-model to space' and was put into practice with studio work, carried out a different pedagogical model than the traditional studio. First of all, this difference started with the abandonment of traditional studio habits and then continued with the transfer of design outcomes based on basic design exercises in the studio. So that the students could internalize the subject, a repetition-based experience area consisting of three weeks was designed. This 3step method provided a dynamic studio setting since the models and phases were changed and interwined. In addition to this, 3-step method was derived from a concrete starting point. This was entirely based on basic design exercises, called as section-model. While section-models were analyzed, deformed and reformed by students in each phase, 3-step method was functioned as a new learning setting. 3-step method contributed to the design process awareness and educational process awareness as a catalyst. Although the section-models were stable, architectural design process and product emerged in a flexible setting since the ability of thinking and doing was changed. Thus, students discovered that how they approached a model and an architectural problem. Design and learning processes were transformed into a research laboratory and at this point, experience was become a primary awareness tool. For example, the process directed the students to do more research in the context of spatial analysis, tectonic and material relations, and further increased the level of interaction in the studio environment. The increased interaction in the studio environment was due to the unique way the same model was analyzed in the other phases. So the process also aroused the phenomenon of curiosity in the studio. On the other hand, the process recalled the basic design exercises (abstraction, deformation, hierarchy, rhythm, etc.) required to bring the current section-model to a consistent formal order. While the process started a thought process on how to organize the form tectonically in the student, students also came to understand that the plan-section-elevation relation should be handled as a whole.

Briefly, this method, which was coded from 'section-model to space', encouraged a new learning environment that differs from 
traditional studio habits in practice. Thus, the method of the integration between basic design exercises and architectural studio, mentioned in the beginning, enhanced the potential of experience and discovery. Architectural studio practice evolved into a learning setup based on design processes. While architectural students were working on different models in different phases, they interacted each other intensely. They shared their experiences on a model which they worked before. This cause learning setup to be interactive and participative milieu. The method enabled more effective processes such as interaction and research to be expected in the architectural studio. Since design stragtegies and design knowledge emerged in the studio, formal analyses and design approaches derived from discovering-experiencing and thinkingdoing processes. From all these aspects, the method from 'section-model to space' has emerged as an applicable process of a learning model in architectural education. For further studies, 'section-model to space' method can be also ameliorated. For example, section-model as a catalyst can be increased or reduced the diversity of architectural production. To provide this, it can be benefitted from behavioural and psychological studies. Thus, design strategies can be analyzed in detail with regards to cognitive, perceptual and formal studies. Apart from this, section-models can be also investigated in terms of building materials as well as tectonic components. Integration details of diffrent materials can be studied more concentrated way. Eventually, 'section-model to space' method can be grasp as a research laboratory on design.

\section{References:}

Alangoya, K. A. (2015). 'Tasarımcı düşünce' geleneğinin maceracı yapısı ve kentsel tasarım eğitimine katkısı üzerine deneysel bir kentsel tasarım stüdyosu: "iz üstünde taksim meydanı" METU JFA, 32 (1), 65-89.

Arnheim, R. (2009). The dynamics of architectural form. ( $2^{\text {nd }}$ ed.). Berkeley-Los Angeles-London: University of California Press.
Asar, H. (2018). Mimari temsil araçlarından maketin tasarım düşüncesindeki yeri. Tasarım ve Kuram Dergisi, 26, 24-35.

Ciravoğlu, A. (2014). Notes on architectural education: an experimental approach to design studio. Social and Behavioral Sciences, 152, 712.

Demirbaş, O. O., \& Demirkan, H. (2003). Focus on architectural design process through learning styles. Design Studies, 24, 437-456.

Galle, P. (2011). Foundational and instrumental design theory. Design Issues, 27(4), 81-94.

Goldschmidt, G. (1983). Doing design, making architecture. JAE, 37(1), 8-13.

Goldschmidt, G. (2017). Design thinking: a method or a gateway into design cognition? The Journal of Design, Economics, and Innovation, 3(2), 107-112.

Oxman, R. (2004). Think-maps: teaching design thinking in design education, Design Studies, 25, 63-91.

Paker Kahvecioğlu, N. (2007). Architectural design studio organization and creativity. ITU A/Z, 4(2), 6-26.

Reynolds, C. (2015). The fourth register of architecture: 'model as...'. (Unpublished M.Arc thesis), The Bartlett School of Architecture, UCL, England.

Salama, A. M. (2015). Spatial design education new directions for pedagogy in architecture and beyond. England \& USA: Ashgate Publishing.

Voet, C. (2013). Research on space as a productive design tool. Proceedings of the Conference Theory by Design Architectural Research Made Explicit in the Design Studio (29-31 October 2012), Antwerp/Belgium: Faculty of Design Sciences, Artesis University College, pp.101-110. 